\title{
COVID-19 Case Fatality Rate: Misapprehended Calculations
}

\author{
Krishna Prasad Acharya ${ }^{1}$ D, Ranjit Sah ${ }^{2 *}$ (D) , Supram Hosuru Subramanya ${ }^{3}$, \\ Dinesh Neupane ${ }^{4}$, Binay Kumar Panjiyar² ${ }^{2}$, Ali A. Rabaan ${ }^{5}$ (D), \\ Kranti Suresh Vora ${ }^{6,7}$, SenthilKumar Natesan ${ }^{6}$ (D), Kuldeep Dhama ${ }^{8}$ \\ and Alfonso J. Rodriguez-Morales ${ }^{9,10,11 *}$ (D)
}

\footnotetext{
${ }^{1}$ Animal Quarantine Office-Kathmandu, Department of Livestock Services, Kathmandu, Nepal. ${ }^{2}$ Tribhuvan University Teaching Hospital, Institute of Medicine, Kathmandu, Nepal. ${ }^{3}$ Manipal College of Medical Sciences, Pokhara, Nepal.

${ }^{4}$ John Hopkins Bloomberg School of Public Health, Baltimore, USA.

${ }^{5}$ Molecular Diagnostic Laboratory, Johns Hopkins Aramco Healthcare, Dhahran, Saudi Arabia.

${ }^{6}$ Department of Infectious Diseases, Indian Institute of Public Health Gandhinagar, Lekawada, Gandhinagar, Gujarat, 382042, India.

${ }^{7}$ Institute of Health Research, University of Canberra, ACT 2617, Australia.

${ }^{8}$ Division of Pathology, ICAR-Indian Veterinary Research Institute, Izatnagar 243 122, Bareilly, Uttar Pradesh, India.

${ }^{9}$ Public Health and Infection Research Group, Faculty of Health Sciences, Universidad Tecnologica de Pereira, Pereira, Risaralda, Colombia.

${ }^{10} \mathrm{Grupo}$ de Investigacion Biomedicina, Faculty of Medicine, Fundacion Universitaria Autonoma de lasAmericas, Sede Pereira, Pereira, Risaralda, Colombia.

${ }^{11}$ School of Medicine, Universidad Privada Franz Tamayo (UNIFRANZ), Cochabamba, Bolivia.
}

*Correspondence: ranjitsah57@gmail.com; arodriguezm@utp.edu.co

(Received: July 12, 2020; accepted: August 17, 2020)

Citation: Acharya KP, Sah R, Subramanya SH, et al. COVID-19 Case Fatality Rate: Misapprehended Calculations. J Pure Appl Microbiol. 2020;14(3):1675-1679. doi: 10.22207/JPAM.14.3.05

C The Author(s) 2020. Open Access. This article is distributed under the terms of the Creative Commons Attribution 4.0 International License which permits unrestricted use, sharing, distribution, and reproduction in any medium, provided you give appropriate credit to the original author(s) and the source, provide a link to the Creative Commons license, and indicate if changes were made. 


\section{INTRODUCTION}

Coronavirus disease 2019 (COVID-19) pandemic, posed by sever acute respiratory syndrome coronavirus - 2 (SARS-CoV-2), is killing tens of thousands of people globally. It is disrupting societies and economies across the globe with widespread uncertainty. As of August 10, 2020, the total cases of COVID-19 have risen above 20 million and death tolls to nearly 0.74 million $^{1}$ with the case fatality rate (CFR) of $3.65^{1}$. The CFR indicates proportion of persons who die from a specified disease out of all individuals diagnosed positive over a specific period. Thus, the CFR is based on the number of deaths and confirmed cases. However, number of confirmed cases is not including asymptomatic cases or patients with mild symptoms, which in turn may not get tested and may not reflect the actual CFR. CFR is also proportionately variable depending on the level of testing done in a population or a country. When testing is done very extensively covering large population including symptomatic patients and non-symptomatic contacts, the denominator of the CFR calculation increases which will reduce the CFR compared to limited testing carried out only on symptomatic patients. Huge variation in the CFR was observed between different countries. The CFR in early stage of the epidemic was $0.15 \%$ (95\% Cl: $0.12-0.18 \%$ ) in China excluding Hubei and $1.41 \%$ (95\% Cl: 1.38-1.45\%) in Hubei province excluding Wuhan city, and it was $5.25 \%(95 \% \mathrm{Cl}$ : 4.98-5.51\%) in Wuhan ${ }^{2}$ named COVID-19, hit a major city of China, Wuhan in December 2019 and subsequently spread to other provinces/regions of China and overseas. Several studies have been done to estimate the basic reproduction number in the early phase of this outbreak, yet there are no reliable estimates of case fatality rate (CFR. The CFR rate of was found very high among countries such as France, Italy, Spain and USA viz., 13.7\%, $13.5 \%, 10.2 \%$, and $5.7 \%$, respectively ${ }^{3}$. Fig. 1 shows CFR of world and selected countries as of $22^{\text {nd }}$ July 2020. It highlights the differences among countries while noting changes in the protocols of testing (www.ourworlddata.org/coronvirus).

The CFR is also influenced by the demographic nature of the population including

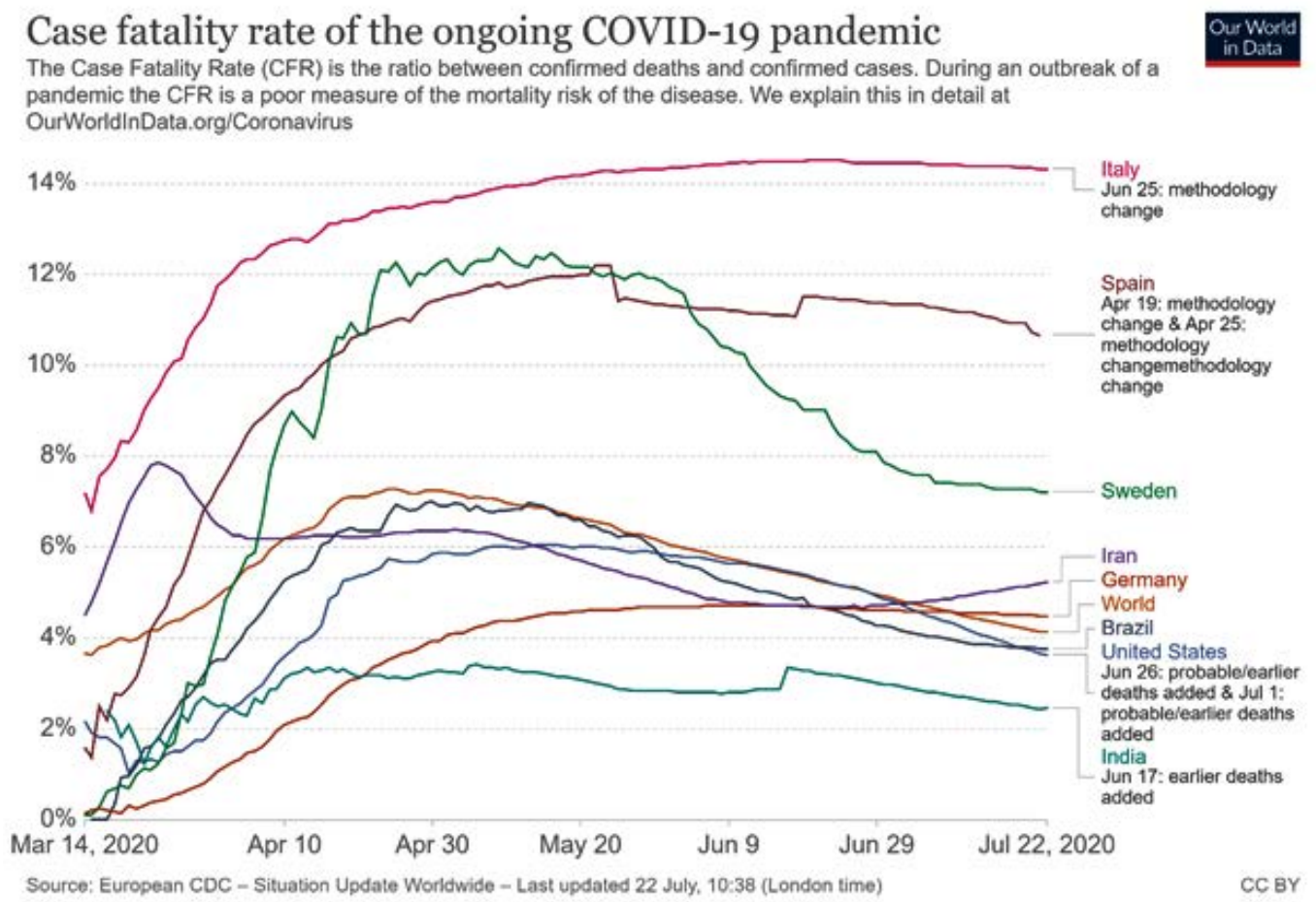

Fig. 1. COVID-19 Case Fatality Rates of World and selected countries as of $22^{\text {nd }}$ July 2020. Assessed from https:// ourworldindata.org. on 23rd July 2020. 
factors such as age and sex of population and underlying co-morbidities. Meta-analysis of the 10 published data showed a fatality rate of $5 \%{ }^{4}$. Different approaches for estimating the CFR accurately has also been suggested ${ }^{5-8}$.

Moreover, confirmed cases included in calculating CFR are derived from the cases which were reported to hospitals or laboratory testing at other places, which is not the accurate representation of total cases of COVID-19. This method is likely to miss the cases not reported to the hospitals because of many mild and asymptomatic cases. Therefore it becomes crucial to assess exact fatality rate by dividing total number of deaths to total number of confirmed cases including patients with mild symptoms, symptomatic as well as asymptomatic cases diagnosed through extensive surveillance using reliable accurate testing ${ }^{9}$. Currently, most countries test only the symptomatic patients with influenza like respiratory symptoms using the RTPCR method of detecting the SARS COV-2 genome.

Onder et al., ${ }^{9}$ identified the fatality rates in COVID-19 patients varying from $1 \%$ to $7 \%$; however, this information must be interpreted with caution because these calculations probably are misapprehended. The variation of CFR might differ from countries to countries, which bring discrepancies in determining overall fatality rates. For example, the massive screening of COVID-19 with very high tests per million of the population was performed in the entire community in South Korea, Singapore, Hongkong, and New Zealand, which had higher chances of detection of mild and asymptomatic cases with the inclusion of both mild and asymptomatic cases in the denominator. That has resulted in less than a 3\% fatality rate ${ }^{1,10,11}$. Conversely, in countries like Italy, Spain, France, screening for COVID-19 was performed only to hospitals (having low tests per million population) attending symptomatic patients and high-risk group $^{12}$, which ultimately decreased the total count of actual cases; thus, more than $10 \%$ CFR was reported as of July $8,2020^{10,11}$.

Spychalski and colleagues suggest CFR overestimation owing to under-testing and time-lag bias ${ }^{13}$. It is, therefore, very crucial to understand the difference between the CFR and infection fatality rate (IFR) before drawing any such conclusions. CFR is the proportion of the number of deaths divided by all confirmed cases by molecular detection method. Infection fatality rate (IFR) is proportion of deaths divided by all infection (includes mild and even asymptomatic individuals). Considering the current selection bias testing strategies, that is, the polymerase chain reaction (PCR) based test is mainly utilized for the detection of individuals with coronavirus symptoms and high-risk patients. Understanding the true IFR has strategic significances for designing control measures for COVID-19. A realistic estimation of CFR is even more important for low- and middle-income countries because of their limited testing capacity, deaths of older people usually occur at home, and there is no proper system to assign the cause of mortality. The Centre for Evidence-Based Medicine (CEBM) at University of Oxford $^{10}$ estimates the CFR globally at $0.51 \%$ and IFR between $0.1 \%$ to $0.26 \%$, with all caveats concerning that.

Though the significant causes of death include respiratory failure, shock, multiple organ failure, actual death process in COCID-19 patients is still poorly understood ${ }^{12}$. Moreover, the effect of the secondary bacterial infection triggering the death of patients is also not well-defined, highlighting that deaths of patients were not just confined to viral infections but also various other parameters. In marginalized and resource-driven countries, they lack medicines, hospital beds, intensive care, mechanical ventilation, extracorporeal membrane oxygenation, vasopressors, and renal replacement. Therefore, the actual death may not be attributed to COVID-19, but due to the lack of necessary equipment and facilities. Also, in high infection zones, patients with trauma or acute brain injury might be admitted to the ICU, who later acquired COVID-19 during the hospital stay and died after that. These deaths are still accountable to COVID-19 ${ }^{12}$. An autopsy study on COVID-19 patients showed advanced diffuse alveolar and superimposed bacterial pneumonia along with changes in organs such as liver and heart ${ }^{14,15}$.

Moreover; some patients are on the verge of death due to the elderly or some other underlying diseases such as cancer or terminal organ failure. In such cases, the COVID-19 infection plays a minimal role in the deaths. Therefore, it becomes difficult to affirm the CFR due to COVID-19 among patients with pre- 
existing comorbidities / illnesses. A study from NewYork city showed that age-adjusted CFRs in cancer patients were significantly higher than non-cancer ones. It showed a CFR of $37 \%$ for hematologic malignancies while $25 \%$ for solid cancers. The increase in mortality among cancer patients due to COVID-19 was markedly related with older age, other comorbidities, elevated profiles of biomarkers such as D-dimer, lactate dehydrogenase, and lactate ${ }^{16}$.

Mortality in mainland China has shown the highest death rates (10.5\%) in patients with cardiovascular disease, then by diabetes $(7.3 \%)$, chronic respiratory disease (6.3\%), hypertension $(6 \%)$, and cancer $(5.6 \%)^{17}$. The study also found that the highest health risk and mortality (14.8\%) were detected in older adults aged over 60 years, while no death was reported in the $0-9$ years age group ${ }^{18}$. However, patients with no pre-existing conditions had fewer death rates (0.9\%). Similarly in the USA, data collected from January 22 to May 30 , 2020, showed the highest mortality rate of $28.7 \%$ in the COVID-19 patients $\geq 80$ years old, whereas $0.1 \%$ deaths in the patients $\leq 19$ years old ${ }^{19}$. Likewise, a mortality rate of $19.5 \%(38,812 / 198,879)$ had been reported in patients with pre-existing illness whereas only $1.6 \%(1,431 / 88,441)$ of COVID-19 patients with no preexisting health illness have died $^{19}$. Similar higher mortality rate of $42.5 \%$ (7558/36398) among the COVID-19 patients with pre-existing illness has also been reported by Khan and his colleagues in their systematic review on COVID-19 patients ${ }^{20}$. These results vividly illustrate that the patients are dying due to pre-existing conditions rather than COVID-19. The actual reporting is lacking since the data regarding pre-existing conditions of COVID-19 patients are confined to very few countries. Most of the reported COVID-19 cases are from the hospitals, which is likely to bias the cases that are not hospitalized. WHO-China Joint Mission on COVID-19 reported that $80 \%$ of 55,924 laboratoryconfirmed COVID-19 patients in China to February 20,2020 , revealed mild disease, both pneumonia and non-pneumonia, whereas $13.8 \%$ reported a severe illness and $6.1 \%$ reached to critical stage demanding intensive $\mathrm{car}^{18}{ }^{18}$. Considering the fact that many observed mild conditions, highest death rates were reported from older people, also those with the pre-existing condition, we can infer that death rates of COVID-19 patients are overestimation than actual. Therefore, it seems like most of the patients are dying "with' COVID-19 rather than "of" COVID-19.

In conclusion, CFR of various countries is variable and it is difficult to judge the change in same. There are several caveats in estimating the CFR currently as there is no uniform approach for SARS-CoV-2 testing for diagnosis of COVID-19. Such lack of uniformity in testing is also contributing to the wide variation in CFR reported from different countries. The patients tested today positive may counted in the confirmed cases, however, their fatality may not be included in the time point when the CFR is estimated. The exclusion of mild or nonsymptomatic patients from testing will also affect the CFR. The number of tests done for a specific number of people in a population should also be considered. All these factors can affect the CFR estimation. Underestimation of CFR may provide a false sense of security and overestimation may lead to panic among people. Therefore, there is a need to follow a standard approach for accurate estimation of CFR which is acceptable across different geographical regions. Based on evidence examined it is suggested to use the total confirmed cases (symptomatic as well as asymptomatic cases) to interpret the actual CFR through an intensive population-based surveillance system using the standard scientific approach. Moreover, it is imperative to investigate the reason and process of deaths of patients, including aspects such as lack of treatment facilities, beds, personnel, equipment, pre-existing conditions (patient's age, pre-existing diseases), and the prevalence of antimicrobial resistance in the region or other demographic information. CFR is an effective measure of diagnostic and treatment capacity of a health system along with surveillance ability. Accurate calculation of CFR is need of the hour to measure the progress made and future actions at the country and global levels.

\section{ACKNOWLEDGMENTS}

All the listed author(s) are thankful to their representative universities/institutes for providing the related support to compile this work. 


\section{CONFLICT OF INTEREST}

The authors declare that there is no conflict of interest.

\section{AUTHORS' CONTRIBUTION}

All the listed author(s) have made a substantial, direct, and intellectual contribution to the work, and approved it for publication.

\section{FUNDING}

None.

\section{ETHICS STATEMENT}

This article does not contain any studies with human participants or animals performed by any of the authors.

\section{DATA AVAILABILITY}

Not applicable.

\section{REFERENCES}

1. Worldmeter. Coronavirus Cases_Statistics and Charts - Worldometer. Published online 2020. https://www. worldometers.info/coronavirus/

2. Yang $\mathrm{S}, \mathrm{Cao} P, \mathrm{Du} P$, et al. Early estimation of the case fatality rate of COVID-19 in mainland China: a datadriven analysis. Ann Trans/ Med. Published online 2020;8(4). doi: 10.21037/atm.2020.02.66

3. Undela K, Gudi SK. Assumptions for disparities in case-fatality rates of coronavirus disease (COVID-19) across the globe. Eur Rev Med Pharmacol Sci. Published online 2020;24:5180-5182. doi: 10.26355/ eurrev_202005_21215

4. Li L quan, Huang $T$, Wang $Y$ qing, et al. CoVID-19 patients' clinical characteristics, discharge rate, and fatality rate of meta-analysis. J Med Virol. Published online 2020;92(6). doi: 10.1002/jmv.25757

5. Baud D, Qi X, Nielsen-Saines K, Musso D, Pomar L, Favre G. Real estimates of mortality following COVID-19 infection. Lancet Infect Dis. Published online 2020;20(7):P773. doi: 10.1016/S14733099(20)30195-X

6. Kim DD, Goel A. Estimating case fatality rates of COVID-19. Lancet Infect Dis. Published online 2020;20(7):P773-774. doi: 10.1016/S14733099(20)30234-6

7. Rajgor DD, Lee $\mathrm{MH}$, Archuleta S, Bagdasarian N, Quek SC. The many estimates of the COVID-19 case fatality rate. Lancet Infect Dis. Published online 2020;20(7):P776-777. doi: 10.1016/S14733099(20)30244-9

8. Soliman AT, Alyafei F, Elalaily R. Covid-19 virus case fatality rate: How to avoid errors in calculation of data during the outbreak? Acta Biomed. Published online
2020;91(2). doi: 10.23750/abm.v91i2.9530

9. Onder G, Rezza G, Brusaferro S. Case-Fatality Rate and Characteristics of Patients Dying in Relation to COVID-19 in Italy. JAMA. 2020323(18)1775-1776. doi: 10.1001/jama.2020.4683

10. CEBM. Global Covid-19 Case Fatality Rates. Published 2020. https://www.cebm.net/covid-19/global-covid19-case-fatality-rates/

11. Euronews. Coronavirus statistics Latest data on COVID-19 infections and deaths. Published online 2020. https://www.euronews.com/2020/07/08/covid19-coronavirus-breakdown-of-deaths-and-infectionsworldwide

12. Vincent JL, Taccone FS. Understanding pathways to death in patients with COVID-19. Lancet Respir Med. Published online 2020;8(5):P430-432. doi: 10.1016/ S2213-2600(20)30165-X

13. Spychalski P, Blazynska-Spychalska A, Kobiela J. Estimating case fatality rates of COVID-19. Lancet Infect Dis. 2020;20(7):P774-775. doi: 10.1016/S14733099(20)30246-2

14. Tian $\mathrm{S}$, Xiong $\mathrm{Y}$, Liu $\mathrm{H}$, et al. Pathological study of the 2019 novel coronavirus disease (COVID-19) through postmortem core biopsies. Mod Pathol. Published online 2020;33:1007-1014. doi: 10.1038/s41379-0200536-x

15. Beigmohammadi MT, Jahanbin $B$, Safaei $M$, et al. Pathological Findings of Postmortem Biopsies From Lung, Heart, and Liver of 7 Deceased COVID-19 Patients. Int I Surg Pathol. 2020. doi: 10.1177/1066896920935195

16. Mehta V, Goel S, Kabarriti R, et al. Case Fatality Rate of Cancer Patients with COVID-19 in a New York Hospital System. Cancer Discov. 2020;1158(2):2159-8290. doi: 10.1158/2159-8290.CD-20-0516

17. Special Expert Group for Control of the Epidemic of Novel Coronavirus Pneumonia of the Chinese Preventive Medicine Association. An update on the epidemiological characteristics of novel coronavirus pneumonia (COVID-19). Zhonghua Liu Xing Bing Xue Za Zhi. 2020;41(2):139-144. doi: 10.3760/cma.j.is sn.0254-6450.2020.02.002

18. WHO. Report of the WHO-China Joint Mission on Coronavirus Disease 2019 (COVID-19). https://www. who.int/docs/default-source/coronaviruse/whochina-joint-mission-on-covid-19-final-report.pdf

19. Stokes EK, Zambrano LD, Anderson KN, et al. Coronavirus Disease 2019 Case Surveillance - United States, January 22-May 30, 2020. MMWR Morb Mortal Wkly Rep. 2020;69(24):759-765. doi: 10.15585/mmwr. mm6924e2

20. Khan M, Khan MN, Mustagir MG, Rana J, Islam MS, Kabir MI. Effects of underlying morbidities on the occurrence of deaths in COVID-19 patients: A systematic review and meta-analysis. Published online 2020:0-27. http:// medrxiv.org/lookup/doi/10.1101/2020.05.08.20095 968\%0Ahttps://www.medrxiv.org/content/medrxiv/ early/2020/05/13/2020.05.08.20095968.full.pdf 